\title{
MULTIDISCIPLINARY STUDIES, SYSTEMS APPROACHES AND PARASITE ECO-EPIDEMIOLOGY: SOMETHING OLD, SOMETHING NEW
}

\author{
GIRAUDOUX P.*, RAOUL F.*, PLEYDELL D.* \& CRAIG P.S.**
}

\section{Summary:}

Parasite requires an understanding of complex transmission systems where individual, population and environmental factors and their interactions can hardly been considered separately. Moreover, the importance of space and time in host population and parasite transmission processes is increasingly recognised. The present review illustrates how epidemiology and transmission ecology have evolved in a multidisciplinary framework to a systems approach that includes both spatial and temporal dimensions. Focusing on population processes, three significant challenges are discussed: (i) integration of landscape ecology concepts and modelling across time-space scales, (ii) development of molecular methods that permits easy parasite/host identification and process tracking (e.g. host and parasite movements), and (iii) integration of sociology methods to estimate zoonotic risk and exposure.

KEY WORDS : landscape ecology, molecular epidemiology, sociology, multiscale parasite transmission.

U nderstanding parasite transmission requires knowledge of the ecological conditions that regulate their population dynamics. This transmission concerns both parasite life cycles and human exposure, especially for zoonotic species, and presents the challenge of understanding the complexity of a life-cycle with a systems approach which must address multiple levels of biological organisation. Euzet and Combes popularized the concept of meeting and compatibility "filters" (or 'screens') to symbolise the mechanisms responsible for sustainable transmission of a parasite (Combes, 2001). The "compatibility" screen relates to host recognition by the parasite and host resistance/susceptibility and is generally studied at cellular, individual and population levels. The "meeting" screen relates to parasite-host encounters at the organism level and is studied in terms of population distributions, dispersion and interactions. Systems characterised by physiologically susceptible hosts populations that are dynamic in

\footnotetext{
* Department of Chrono-environment, University of Franche-Comté, UMR CNRS 6249 usc INRA, 1, place Leclerc, F-25030 Besançon cedex, France.

**: Biosciences Research Institute, School of Environment and Life Sciences, University of Salford, Manchester M5 4WT, UK. Correspondence: Patrick Giraudoux.

Tel.: +33 (0)3 81665745 - Fax: +33 (0)3 81665797.

E-mail: patrick.giraudoux@univ-fcomte.fr
}

time and space require that transmission studies focus also on the "meeting" screen. Understanding how a parasite passes the "meeting" screen involves various fields of ecology: landscape and community ecology, population dynamics (with important modelling components), ethology and ecophysiology. It should also involve sociology as long as human parasites are concerned. Thus, several fields of science are obviously required at each level of organisation. Moreover, to understand parasite transmission in the real world means to understand a complex transmission system where individual, population and environmental factors can hardly be considered separately (Sholthof, 2007). Although many fields of science contribute to parasitology, the number of articles addressing the complexity of transmission systems in itself and syntheses on this subject is relatively low compared to more specialised issues of parasitology. Furthermore, even fewer addressing complexity are based on multidisciplinary studies. For instance, a query of the Scopus data base on parasite/parasitology identifies 497 articles also indexed on complexity from 1973 to 2006 while only 66 were indexed on multidisciplinary over the same period. In both cases $50 \%$ of them were
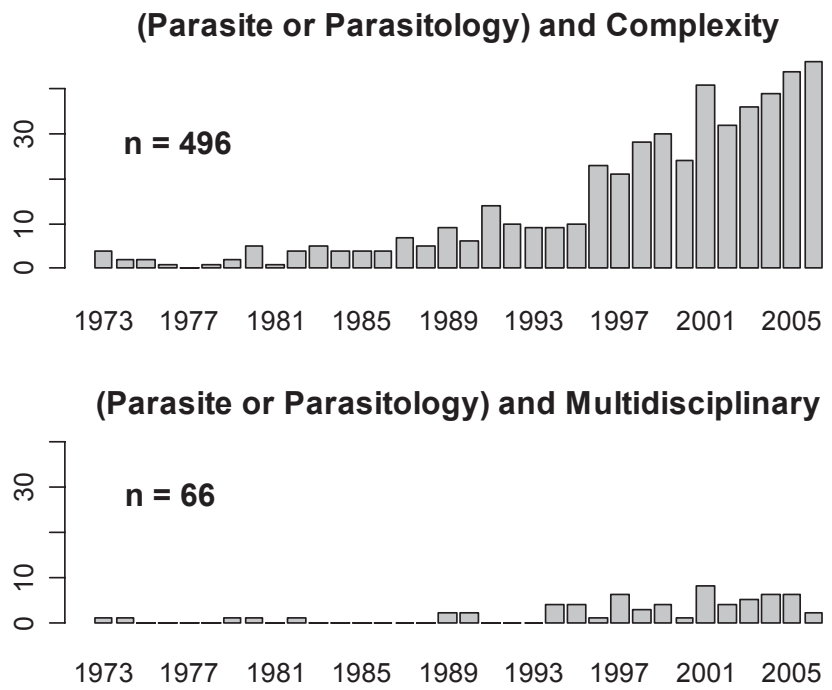

Fig. 1. - Number of articles from 1973 to 2006 indexed on Parasite, Parasitology, Complexity and Multisciplinary $\left(\right.$ Scopus $^{\odot}$ database). 
published after 2000, indicating that complexity and multidisciplinary are issues of increasing interest recently (Fig. 1). Of course the validity of picturing the scarcity of multidisciplinary studies in this manner is debatable since studies on complexity that may be intrinsically multidisciplinary may well not have been indexed with these key words. However, the pattern does provide a striking illustration of recent climatic change within the scientific community by revealing a recent augmentation of interest among scientists for such studies.

Furthermore, the importance of space and time in population processes is increasingly recognised. In many cases sub-populations of interest do not exist in isolation but interact, via dispersal, with other conspecific sub-populations across a larger region. In this case, the inadequacy of traditional (e.g. non-spatial) approaches to determining population and transmission dynamics is obvious. In 1970, Richard Levins coined the term metapopulation for a set of population patches within larger areas of space, with long-term survival of the species depending on a shifting balance between local extinctions and recolonizations in the patchwork (Hanski, 1998, 1999). Landscape ecology incorporates metapopulation concepts and focuses on the spatial relationships among landscape elements, the population dynamics of species among the elements, and the ecological dynamics of the landscape mosaic through time. It also provides a challenging framework for the study of host - parasite interactions.

Describing patterns and disclosing processes over large areas and long time periods are undoubtedly targets shared by both human/veterinary epidemiologists and population/community ecologists. In doing so, they combine information provided by molecular biologists, immunologists, clinicians, veterinarians, wildlife biologists, geographers and sociologists in various kinds of models (not all mathematical) and aim at integrating heterogeneous data in a consistent framework.

The aim of this paper is to illustrate, based on some examples, how such eco-epidemiological approaches have been used to help understand parasite transmission systems, and to discuss some forthcoming challenges where both spatial and temporal dimensions must be specifically taken into account.

\section{BRIEF HISTORICAL PERSPECTIVE}

The combination of several heterogeneous observations to disclose the mechanisms of infectious organism transmission is not really new. The discovery of the route for anthrax transmission by Louis Pasteur, Charles Chamberland and Emile Roux at the "Champs maudits" (doomed fields), in the Chartres countryside of France, was of this kind (Gascar, 1986). There, local peasants made the relationship between places where ground colour between grasses was not exactly normal and the fact that animals bred in those pastures often died from disease. In August 1878, Roux and Chamberland, sent by Pasteur, walked slowly and tirelessly across fields and remarked that those areas were spotted with small earth twists expelled by earthworms. Microscopic examination showed the bacteria. However, it did not explain how sheep could be infected (experimental infection of naive animals did not lead them to get anthrax): new enigma! Thorough examination of animals that died from anthrax showed small mouth lesions provoked by chewing thistles or sharp edged grasses. Most of the elements of a multidisciplinary study were gathered in this story. Transmission was studied in a systems approach, and this study was based on collecting empirical data in the real world (Les champs maudits) where epidemics occurred, to reassemble them into a consistent theory (nowadays, one would read "conceptual model"). Pasteur was a chemist, Chamberland a biologist and physicist and Roux a medical physician. Information coming from common people having faced the disease for years was not neglected but acted upon and augmented with complementary information gleamed from systematic observation. These observations then helped form hypotheses which were then subjected to experimental investigation. Negative results formed a basis for new empirical observations and so on. This scheme has been the starting point of the success story of the "Pastorians" in their early years which also encompassed the discovery of the mechanisms of plague transmission by Alexandre Yersin, of malaria, suspected by Emile Marchoux then formally confirmed by Ronald Ross, of typhus by Charles Nicolle, etc. The common traits of those approaches were: $i$ ) to take natural complex systems as a whole, and to reassemble empirical data from these systems to build hypothesis models and to organise them holistically; $i$ ) to test models by experimentation and to reorganise hypotheses via a continuous exchange between theory, observations and experimental results. At every moment of a specific experiment the system as a whole was in mind.

\section{THE EARLY YEARS}

ystems approaches in transmission studies were reactivated in the second half of the twentieth $\cup$ century. One such study was initiated by French medical doctors whose training at that time had included zoology and botany (ecology was not taught as an organized discipline during that epoch). Golvan \& Rioux (1961, 1963) showed that plague epidemics in the Iranian Kurdistan were due to a resistant stable populations of gerbils (Meriones persicus), living in 
rocky areas, and serving as a stable reservoir, that transfer the bacillus (Yersinia pestis) to an unstable sensitive populations of Meriones vinogradovi living in farmland. During population surges of the latter, dispersal of some individuals from farmland to suboptimal rocky habitats was found to open the meeting screen between $M$. vinogradovi and fleas of $M$. persicus giving rise to fresh waves of infection and a new epizootic in $M$. vinogradovi population leading to sharp declines in numbers leading to virtual extinction. During the high density phases of the population cycle, crop damage was severe and people compensated for losses by digging up the caches of cereals gathered by gerbils (several kilos per den). This practice, and the subsequent "imprudent handling of dead gerbils", increased the risk for human contamination (Combes, 2001). In this case most of the key-issues challenging current research were already present: the importance of space (transmission is explained by species movements between habitats), importance of time (disease transmission dynamics depends on host population temporal dynamics), importance of species sensitivity (plague is stable there because one population is resistant), importance of human behaviour (which explains human exposure). However, reading the original paper, it is striking to see that most of the current tools of modern epidemiology were absent (e.g. GIS, mathematical modelling, molecular taxonomy, etc.).

The term "landscape epidemiology" was coined in early works of Pavlowski (1964). Later, Darling (1970) contributed to the field by highlighting some of the interfaces between ecology and medicine. This theme was pursued by Rioux who studied: intestinal schistosomiasis in Guadeloupe (Rioux et al., 1977), leishmaniases in Southern France (Rioux et al., 1969) and North Africa (Rioux et al., 1977) and mosquitoes ecology for control in Southern France (Rioux et al., 1967). In those works he conceptualized how ecological and epidemiological concepts and methods could be combined to ground parasite transmission studies and control programmes (Rioux et al., 1981). He coined the term "eco-epidemiology" for systems approaches integrating methods inherited from both ecology and epidemiology and his approach focused on the definition of a spatial risk, a temporal risk and a population risk (related to population age structure, immunology, etc.). He also stressed the importance of spatial and temporal scales relative to transmission issues (Rioux et al., 1990). His approach was mostly grounded on ecological strata defined from composite maps elaborated from both existing maps (topography, soils, vegetation, etc.) and field data (vector population densities, etc.). Again at that time, GIS, map algebra and sophisticated spatial statistics were still not popular. The link with the Zuricho-Montpellieran phytosociology school which was at its peak was obvious. Vegetation maps seen as indica-

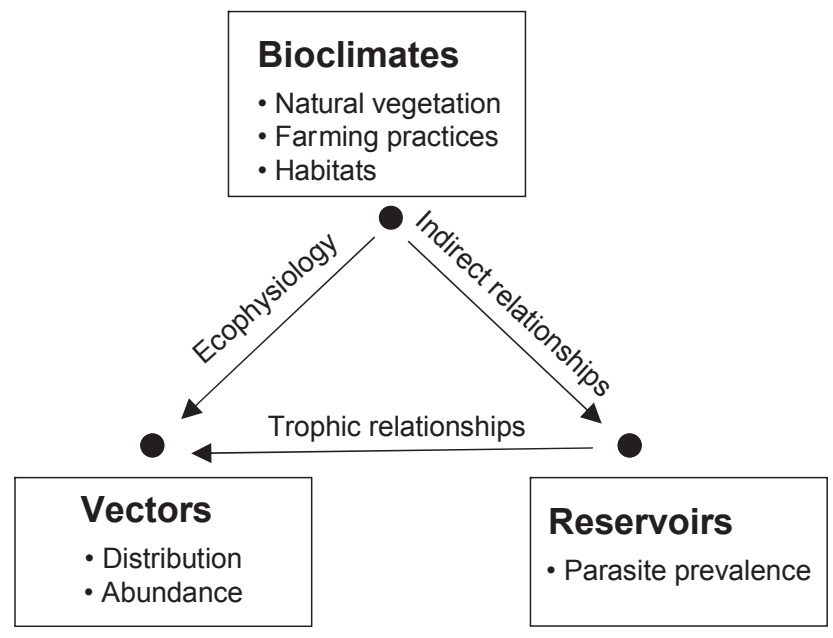

Fig. 2. - Triangular conceptual model of circum-mediterranean leishmaniasis transmission. Bioclimats are revealed from plant species association analysis. Plant associations are correlated to vector distribution and abundance and indirectly determine population reservoir infection (here dogs or small mammals). After Rioux et al. (1997)

tors of ecological conditions were the elective support for example to identifying e.g. vector areas (Fig. 2) and to refer transmission systems to explicit spatial scales (local and regional, in general). Furthermore, multivariate exploratory analysis methods, which were popular in phytosociology to analyse "habitats x species" matrices, were used for the analysis of insect vector distribution in a multivariate context (Rioux et al., 1997; Rioux, 2001). Epidemiology and ecology concepts were integrated as were the modelling and statistical approaches already adopted within the two disciplines.

\section{CURRENT CHALLENGES}

U nderstanding and predicting the effect of anticipated global changes is currently one of the big challenges of science and this concern is arguably less present in the examples mentioned above (however see Rioux et al., 1997)). The principal concern lying at the interface of parasite transmission and epidemiological systems is to understand how environmental events, such as habitat alteration, loss of biodiversity, biological invasion, climate change and pollution, alter the risks of emergence and transmission of parasites (see e.g the Millennium Ecosystem Assessment reports, http://www.millenniumassessment.org). How can epidemiology be more innovative in this context? Probably in cultivating more cross-links with other disciplines especially ecology and molecular biology and in draining renewed computing and modelling capacities from mathematics and statistics. An additional challenge will be to use and develop concepts and high tech methods that have the potential to live for themselves within a whole-systems epidemiology. 
That is to harness the power of technical advances, perhaps in highly specialised sub-disciplines, but keeping the whole system in mind and providing real contributions to a global understanding. Figure 3 shows how the view of the zoonotic cestode, Echinococcus multilocularis, has evolved during the recent years and stresses the importance of a system view with consideration of spatial and temporal scales and processes. However, this growing recognition of the importance of scale issues has still not led to an operative approach permitting to handle/model parasite transmission at multiple temporal and spatial scales, integrating processes up and down across scales while still retaining a view on the whole system.

Ecologists have attempted to theorize and describe the way processes are organized in nested hierarchies long since Allen \& Starr (1982). They have recognised that to carry out investigations at several scales simultaneously it is essential to understand the full set of constraints that determine observed patterns and processes. Indeed, the spatial and temporal scales of investigations determine the range of patterns and processes that may be detected and therefore the level of understanding and explanation that can be achieved.
Observations made within one scale may even have limited power to explain patterns and processes observed even at this scale (see e.g. Giller \& Gee, 1987). For instance, in the parasite world, observing transmission intensity on a small time span of some months can be misleading in areas where multi-annual intermediate host population cycles occur. E. multilocularis transmission can be provisory interrupted during the low density phases of small mammal intermediate host population cycles, which may contrast with high prevalence rates observed at the same time in humans in the same area (human infection observed at population level at a given time, is the result of cumulative events that occurred during preceding decades) (Craig et al., 2000; Giraudoux et al., 2002). Furthermore, after the early insights provided by island biogeography about the effect of space on community processes (MacArthur \& Wilson, 1967), landscape ecology specifically addresses how a range of ecological processes interact in space and time. This approach mainly concerns a high level of biological organisation such as large ecosystems and spatial arrays of interacting communities (Wiens et al., 2007) and thus also applies to complex parasite transmission systems. One of the

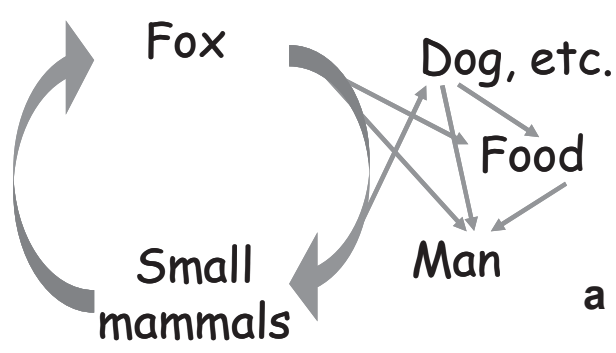

Fig. 3. - Evolution of E. multilocularis transmission picturing. The "classical" parasitological cycle of the 90s (a) has shifted to a more complex box system explicitly featuring population and ecological direct and indirect processes governing transmission (b). Adding an explicit reference to the nested hierarchy of spatial scales at which various processes occur (c) makes the conceptual model much more complex, although temporal dimension is not represented. After Giraudoux et al. (2003, 2006).
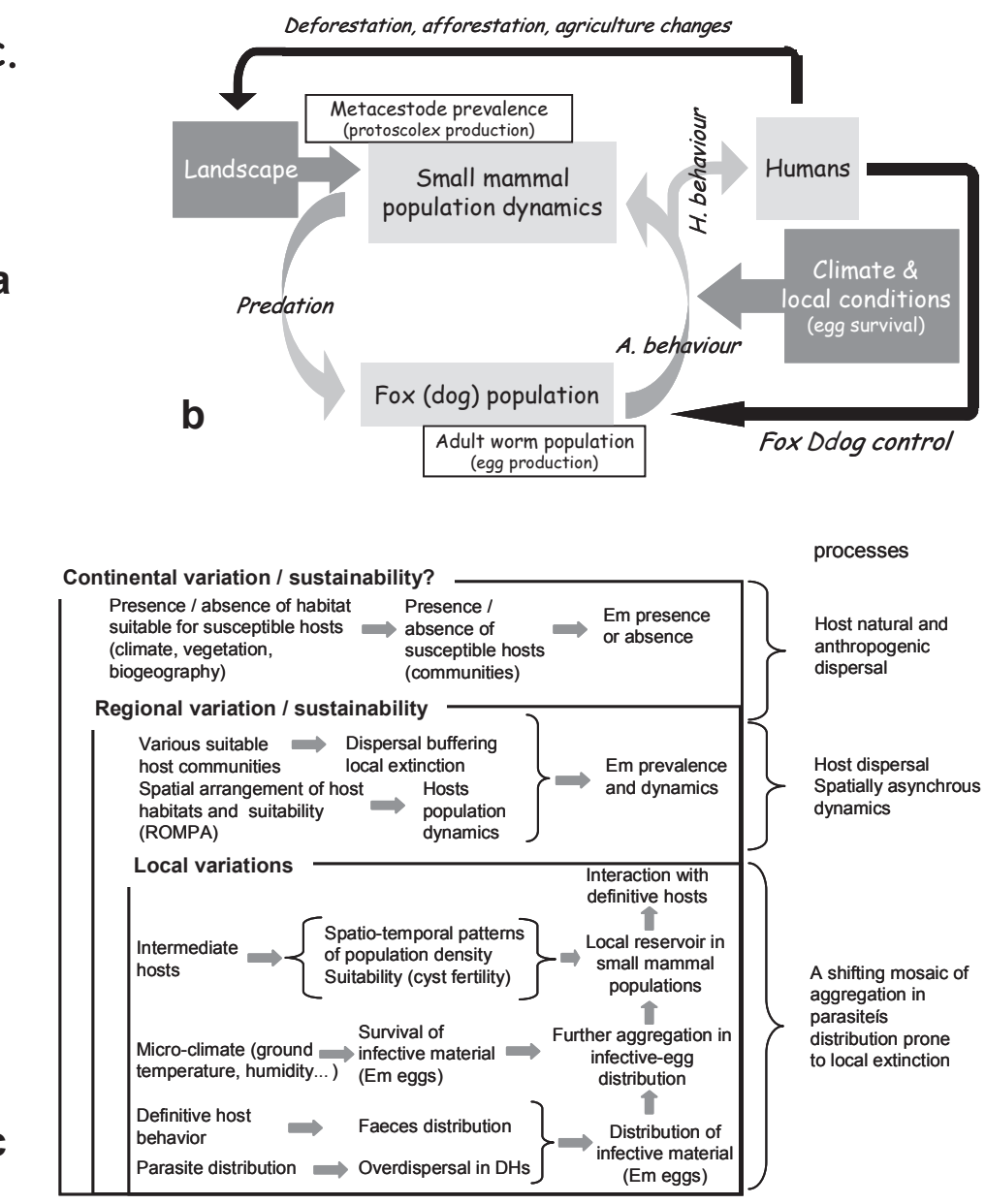
big forthcoming challenges is likely to be how to better link concepts and methods emerging from the fields of ecology, population dynamics and epidemiological studies in parasite transmission (Kitron, 1998; Holdenrieder et al., 2004; Ostfeld et al., 2005).

A number of new methods and technologies have become widely adopted since the mid 1990s and these hold the potential to renew eco-epidemiological approaches of parasite transmission within this conceptual framework.

The use of remote sensing and multi-layered composite data sets using GIS to detect correlations between environmental factors and disease prevalence has, after thirty years of maturation, become a well established practice (Hay et al., 2000; Beck et al., 2002; Durr \& Gattrel, 2004; Brooker et al., 2006). GIS has been successfully used for studying vector borne parasite distribution and to design subsequent control interventions including land management. Indeed, invertebrate vectors are extremely sensitive to changes in temperature and humidity conditions, which can be indirectly measured from soil/vegetation reflectance. The increased availability of satellite data and spatial databases has allowed the production of improved environmental maps and to confront them to ecological, human or veterinary data collected on the ground. For instance, a large number of studies have been achieved on the distribution of trypanosomiasis in Africa, some on a multiscale basis (e.g. Rogers, 2000; Hendrickx et al., 2001; de La Rocque et al., 2005) and this has led to management recommendations (de La Rocque et al., 2001). GIS and satellite imagery have also been used for studying, among others, malaria (Hay et al., 1998; Malone et al., 2006; Rogers, 2002), Triatoma infestans, the vector of Trypanosoma cruzi (Cecere et al., 2004), American visceral leishmaniasis (Bavia et al., 2005), Old world cutaneous leishmaniasis (Cross et al., 1996), Biomphalaria spp., the snail-host of Schistosoma spp. and Fasciola spp (Kristensen et al., 2001; Yang et al., 2005), onchocerciasis (Gebre-Michael et al., 2005), Echinococcus multilocularis (Danson et al., 2004; Pleydell et al., 2004; Danson et al., 2006), Old World screwworm myiasis (Siddig et al., 2005), and Bancroftian filariasis (Hassan, 2004), not to mention the many studies conducted on virus vector-borne diseases (blue tongue, Hanta, La Crosse, West Nile, Sin Nombre, Rift Valley fever and tick-borne viruses, etc.) and some bacteria (e.g. cholera and leprosy).

However, one of the big limits in studies of parasite cycles including a wildlife component, is the fact that population biologists do not have fully reliable tools for estimating host and parasite populations in terms of absolute densities with high precision over large areas, which is required for deterministic models. This most often leads to the use of estimates of relative abundance (e.g. grounded on indirect indices of real densities), which are supposed to be robust enough to allow comparisons. Therefore two conflicting goals are faced designing such studies. On the one hand, it would be nice to have very narrow confidence intervals on density or prevalence estimates in (space and time) locations. The collection of such data is demanding and thus time-consuming. On the other hand to focus heavily on a small number of locations means one can never see the bigger picture (which may reveal e.g. spatial trends or local clusters) and will probably fail to understand transmission at other extremely informative places. Probably the key advantage in spatial approaches and statistics over classical statistics is that one can reach a kind of compromise. One no longer needs to focus all attention on a small number of locations so that single location-level confidence intervals are small. The reason is because with a spatial/temporal model when one estimates a confidence interval at a location all the data from neighbouring location is also used to help tighten that confidence interval. This is of great value because it means one is freer than before to sample a greater number of locations without risking loosing too much statistical power in any one location. Also from the point of view of an eco-epidemiology study it is good to remember that when it comes to analysing landscape effects on epidemiological data it is desirable to have a dataset which includes as much variation in landscape and locations as possible, so a large number of sampled locations is desirable. Thus, spatial modelling and statistics are probably one of the fields of science that can provide improved exploratory tools to eco-epidemiologists. Beyond their proven power for disclosing distribution patterns, it would be essential, focusing on processes, to better link landscape metrics (that can be obtained from remote sensing data) to population dynamics and landscape processes (requiring long term monitoring) in order to better understand how the variation in parasite transmission intensity may be linked to variations in host populations over space and time. For instance, population dynamics of small mammal populations (thus their density variations over time) not only respond to the availability of suitable habitats to a focal species, but also to the ratio of its optimal habitat to the total land area and by the effects of neighbouring sub-optimal habitats (Lidicker, 2000). This can impact tranmission processes in systems where various small mammal communities in contrasted landscapes are key-reservoirs for parasites such as Echinococcus multilocularis (Giraudoux et al., 2003). Furthermore, to upscale results obtained on the limited areas where human population and animal community data can actually be collected to larger areas across scales is still an open challenge. Whether modelling tools will be enough to enable population biologists and epidemiologists to make a better use of scarce and imperfect data at a given scale 
to upscale to larger areas is still an open debate and ongoing research should help answer this important question (Hendrickx et al., 2001; Giraudoux et al., 2007). Molecular methods have also changed the way people are working in ecology and epidemiology especially improving diagnostic and parasite classification systems (Traub et al., 2005; de Meeûs et al., 2007). This is also the case for host studies especially in countries or regions where host taxonomy is not well characterized and where classical taxonomy capabilities have critically decreased to a small number of people where they still exist. Molecular methods have also helped understand how host genetics may increase the risk of infection (Godot et al., 2000; Yang et al., 2006). No less than 5,597 articles, among them 984 reviews, came out with the key word "molecular epidemiology" in PubMed $^{\circ}$ to date. However, only 89 of them (21 reviews) were indexed on "parasite" and still fewer studies were grounded on a spatially explicit approach to parasite and host distributions (but see Kyes et al., 1997). This maybe a gross underestimation due to improper indexing, however, it may also reflects the fact that molecular tools that can relevantly address transmission issues in a spatial context are still at the development stage and that the ones available may be still underused by landscape epidemiologists. For instance, as far as transmission processes are dependent on individual movements of hosts (a general case are metapopulations), to know the distance at which host may disperse and the patterns in such dispersal remains a critical issue. These parameters are not accessible to classical methods of ecology (e.g. capture - mark recapture of animals) essentially due to the fact that the probability of recapturing an animal marked decreases with the square of the distance to where it has been released, preventing any recapture at far distance (not to mention the uncertainty about its behaviour after release...). O'Loughlin et al. (2007) have recently shown how the genetic structure of populations of the malarian vector Anopheles scanloni reveals that the population is actually made of discrete subpopulations limited to limestone-karst habitats with restricted gene flow. Another example can be provided regarding E. multilocularis transmission in China where understanding the ways in which discrete foci within a variety of small mammal communities may be linked at continental scale remains a key challenge. For obvious technical and logistic reasons it is unlikely that this issue can be addressed directly via the study of definitive host dispersal (fox and dog). An alternate solution however is to investigate the spatial variation in genetic structure of georeferenced samples of parasite and host populations from different regions. Thus, it is expected that further advances in parasite and transmission ecology will come from molecular markers and methods that may be developed for exploring a fine grain polymorphism of parasite and host population in a spatial context (Giraudoux et al., 2006).

Finally, systems approaches of anthropozoonoses transmission should also incorporate the variability of human behaviour. For instance, studies on E. multilocularis in China have identified landscape patterns and ecological processes that may be conducive to more intensive transmission and human exposure (Giraudoux et al., 2003; Danson et al., 2006). However, the large variability (0-15\%) of human alveolar echinococcosis among villages in areas of high endemicity remained unexplained and may well be due to undisclosed behavioural differences between villages. Indeed, classical epidemiology (e.g. epidemiological questionnaires and case control studies) carried out by scientists who are often culturally far from their studied communities is likely to miss important details of life traits that may hold hidden keys to understanding exposure. For example, data quality is not always guaranteed with questionnaires designed in the absence of in depth knowledge of cultural traditions and habits. Such uncertainties can escalate when language barriers necessitate one or more translations at which juncture it becomes hard to verify certain information. Thus, the inclusion of social sciences and their articulation to other studies on transmission systems is required although examples of such integration within a systems approach remain scarce to date if even done at all (Cohen et al., 2007) and indeed how to do that whilst keeping a global view on the whole multi-scale transmission system remains an open question.

\section{ACKNOWLEDGEMENTS}

inancial support from the US National Institutes $\checkmark$ of Health from the Fogarty International Center 1 (EID TW001565-05). The content is solely the responsibility of the authors and does not necessarily represent the official views of the Fogarty International Center or the National Institutes of Health. Thanks to W.Z. Lidicker Jr who helped to improve the early version of the manuscript.

\section{REFERENCES}

Allen T.F.H. \& T.B. S. Hierarchy: perspectives for ecological complexity. The University of Chicago Press, 1982, 310.

Bavia M., Carneiro D., Gurgel Hda C., Madureira Filho C. \& BARBOSA M. Remote sensing and geographic information systems and risk of American visceral leishmaniasis in Bahia, Brazil. Parassitologia, 2005, 47, 165-169.

Beck L., Boво M. \& Kitron U. Remote sensing, GIS and landscape ecology: means for studying disease and global change, in: Environmental change, climate and health: 
issues and research methods. Martens P., McMichael T. (eds), Cambridge University Press, 2002, 226-252.

Brooker S., Clements A. \& Bundy D. Global epidemiology, ecology and control of soil-transmitted helminth infections. Advances in Parasitology, 2006, 62, 221-261.

Cecere M.C., Gonzalo M., Vazquez-Prokopec M., Gürtler R.E. \& KITRON U. Spatio-temporal analysis of reinfestation by Triatoma infestans (Hemiptera: reduviidae) following insecticide spraying in a rural community in North Western Argentina. American Journal of Tropical Medicine and Hygiene, 2004, 71 (6), 803-810.

Cohen J., Wilson M. \& Aiello A. Analysis of social epidemiology research on infectious diseases: historical patterns and future opportunities. Journal of epidemiology and community bealth, 2007, 71 (12), 1021-1027.

Combes C. Parasitism. The ecology and evolution of intimate interactions. The University of Chicago Press, Chicago and London, 2001, 728.

Craig P.S., Giraudoux P., Shi D., Bartholomot B., Barnish G., Delattre P., Quéré J. P., Harraga S., Bao G., Wang Y.H., Lu F., Ito A. \& VuitTon D.A. An epidemiological and ecological study of human alveolar echinococcosis transmission in south Gansu, China. Acta tropica, 2000, 77 (2), 167177.

Cross E., Newcomb W. \& Tucker C. Use of weather data and remote sensing to predict the geographic and seasonal distribution of Phlebotomus papatasi in southwest Asia. American Journal of Tropical Medicine and Hygien, 1996, 54, 530-536.

Danson F.M., Craig P.S., Man W., Shi D. \& Giraudoux P. Landscape dynamics and risk modelling of human alveolar echinococcosis. Photogrammetric Engineering and Remote Sensing, 2004, 70 (3), 359-366.

Danson F.M., Giraudoux P. \& Craig P. Spatial modelling and ecology of Echinococcus multilocularis transmission in China. Parasitology International, 2006, 55 (Suppl.), 227231.

DARLING F.F. Bordelines of medicine and ecology. Proceedings of The Royal Society of Medicine, 1970, 63, 1164-1168.

de la Rocque S., Michel F.C., Cuisance D., De Wispelaere C., Solano P., Augusseau X., Arbaud M. \& Guillobez S. Du satellite au microsatellite. Le risque trypanosomien. Une approche globale pour une décision locale. CIRAD, Montpellier, 2001, $151 \mathrm{p}$.

de la Rocque S., Michel J., Bouyer J., De Wispelaere G. \& CuISANCE D. Geographical Information Systems in parasitology: a review of potential applications using the example of animal trypanosomosis in West Africa. Parassitologia, 2005, 47 (1), 97-104.

de Meeûs T., McCoy K., Prugnolle F., Chevillon C., Durand P., Hurtrez-Bousses S. \& Renaud F. Population genetics and molecular epidemiology or how to "débusquer la bête". Infect. Genet. Evol., 2007, 7 (2), 308-332.

DurR P.A. \& GatTrel C. GIS and spatial analysis in veterinary sciences. CABI Publishing, Wallingford, 2004.

Gascar P. Du côté de chez Monsieur Pasteur. Éditions Odile Jacob, Paris, 1986, 379 p.
Gebre-Michael T., Malone J. \& McNally K. Use of Geographic Information Systems in the development of prediction models for onchocerciasis control in Ethiopia. Parassitologia, 2005, 47, 135-144.

Giller P.S. \& GEE J.H.R. The analysis of community organization: the influence of equilibrium, scale and terminology, in: Organization and communities: past and present. Gee J.H.R. \& Giller P.S. (eds), Blaxkwell Scientific Publications, Oxford, 1987, 519-542.

Giraudoux P., Craig P.S., Delattre P., Bartholomot B., Bao G., Barnish G., Harraga S., Quéré J.P., Raoul F., Wang Y.H., SHI D. \& VuitTon D. Interactions between landscape changes and host communities can regulate Echinococcus multilocularis transmission. Parasitology, 2003, 127, 121131.

Giraudoux P., Delattre P., Takahashi K., Raoul F., Quéré J.P., Craig P. \& Vuitton D. Transmission ecology of Echinococcus multilocularis in wildlife: what can be learned from comparative studies and multi-scale approaches? in: Cestode zoonoses: echinococcosis and cysticercosis. An emergent and global problem. Craig P. \& Pawlowski Z. (eds). IOS Press, Amsterdam, 2002, 267-285.

Giraudoux P., Pleydell D., Raoul F., Quéré J.P., Wang Q., YANG Y., VuitTon D., QIU J., YANG W. \& CRAig P.S. Transmission ecology of Echinococcus multilocularis: what are the ranges of parasite stability among various host communities in China? Parasitology International, 2006, 55 (suppl.), 237-246.

Giraudoux P., Pleydell D., Raoul F., Vaniscotte A., Ito A. \& CRAIG P. Echinococcus multilocularis: why are multidisciplinary and multiscale approaches essential in infectious disease ecology? Tropical Medicine and Health, 2007, in press.

Godot V., Harraga S., Beurton I., Tiberghien P., Sarciron E., GotTSTeIn B. \& VutTTON D. Resistance/susceptibility to Echinococcus multilocularis infection and cytokine profile in humans. II. Influence of the HLA B8, DR3, DQ2 haplotype. Clinical and Experimental Immunology, 2000, 121 (3), 491-498.

Golvan Y.J. \& Rioux J.A. Ecologie des mérions du Kurdistan Iranien : relations avec l'épidémiologie de la peste rurale. Annales de Parasitologie Humaine et Comparée, 1961, 36, 449-558.

Golvan Y.J. \& Rioux J.A. La peste, facteur de régulation des populations de mérions au Kurdistan iranien. Revue d'Écologie, Terre Vie, 1963, 1, 3-34.

Hanski I. Metapopulation ecology. Oxford University Press, 1999, 313 p.

Hanski L. Metapopulation dynamics. Nature, 1998, 396, 4149.

Hassan A.N. Bancroftian filariasis: spatial patterns, environmental correlates and landscape predictors of disease risk. Journal of the Egyptian Society for Parasitology, 2004, 34 (2), 501-513.

Hay S.I., Randolph S.E. \& Rogers D.J. Remote sensing and geographical information systems in epidemiology, in: Advances in Parasitology, Vol. 47. Baker J.R., Muller R. \& Rollinson D, Academic Press, London, 2000. 
Hay S.I., SNOw R.W. \& Rogers D.J. From predicting mosquito habitat to malaria seasons using remotely sensed data: practice, problems and perspectives. Parasitology Today, 1998, 14, 306- 313.

Hendrickx G., de La Rocque S., Reid R. \& Wint W. Spatial trypanosomosis management: from data-layers to decision making. Trends in Parasitology, 2001, 17 (1), 35-41.

Holdenrieder O., Pautasso M., Weisberg P. J. \& Lonsdale D. Tree diseases and landscape processes: the challenge of landscape pathology. Trends In Ecology And Evolution, 2004, 19, 446-452.

KITRON U. Landscape ecology and epidemiology of vectorborne diseases: tools for spatial analysis. Journal of Medical Entomology, 1998, 35, 435-445.

Kristensen T., Malone J. \& McCarroll J. Use of satellite remote sensing and geographic information systems to model the distribution and abundance of snail intermediate hosts in Africa: a preliminary model for Biomphalaria pfeifferi in Ethiopia. Acta Tropica, 2001, 79, 73-78.

Kyes S., Harding R., Black G., Craig A., Peshu N., Newbold C. \& MARSH K. Limited spatial clustering of individual Plasmodium falciparum alleles in field isolates from coastal Kenya. American Journal of Tropical Medicine and Hygiene, 1997, 57 (2), 205-215.

LIDICKER W.Z. A food web/landscape interaction model for Microtine density cycles. Oikos, 2000, 91, 432-445.

MacArthur R. \& Wilson E. The theory of island biogeography. Princeton University Press, 1967.

Malone J., Nieto P. \& Tadesse A. Biology-based mapping of vector-borne parasites by geographic information systems and remote sensing. Parassitologia, 2006, 48 (1-2), 77-79.

O'Loughlin S.M., Somboon P. \& Walton C. High levels of population structure caused by habitat islands in the malarial vector Anopheles scanloni. Heredity, 2007, 99, 31-40.

OstFeld R., Glass G. \& KeEsing F. Spatial epidemiology: an emerging (or re-emerging) discipline. Trends in Ecology and Evolution, 2005, 20 (6), 328-336.

PAVlowski E.N. Natural foci of transmission diseases in connexion with the landscape epidemiology of zooanthropozoonses. Nauka, Moscow-Leningrad, 1964, 213 p.

Pleydell D.R.J., Raoul F., Danson F.M., Graham A., Craig P.S., Tourneux F. \& Giraudoux P. Modelling the spatial distribution of Echinococcus multilocularis infection in foxes. Acta Tropica, 2004, 91, 253-265.

Rioux J.A. Trente ans de coopération franco-marocaine sur les leishmanioses : dépistage et analyse des foyers. Facteurs de risque. Changements climatiques et dynamiques noso-géographiques. Bulletin de l'Association des Anciens Élèves de l'Institut Pasteur, 2001, 168, 90-101.

Rioux J.A., Akalay O., Périeres J., Dereure J., Mahjour H.N., le Houérou H.N., Léger N., Desjeux P., Gallego M., SaDDiKi A., Barkia A. \& NACHI H. L'évaluation éco-épidémiologique du "risque leishmanien" au Sahara atlantique marocain. Intérêt heuristique de la relation "phlébotomesbioclimats". Ecologia mediterranea, 1997, 23 (3/4), 73-92.

Rioux J.A., Croset H., Corre J.J., Simmoneau P. \& Gras G. Les bases phytoécologiques de la lutte anti-culicidienne. Car- tographie des biotopes larvaires. Annales de Parasitologie Humaine et Comparée, 1967, 42, 665-680.

Rioux J.A., Croset H. \& Lanotte G. Écologie d'un foyer méditerranéen de leishmaniose viscérale. Essais de modélisation, in: Colloques Leishmanioses 1974 Colloque internationaux du CNRS, Montpellier, 1977.

Rioux J.A., Decamps H., Lanotte J., Combes C., Théron A., Pointier J.F., Seytor S., Delattre P. \& Bougerol C. Écologie de la schitosomose en Guadeloupe. Analyse du système épidémiologique. Documents pour un essais de modélisation. Revue d'Epiédmiologie et Santé Publique, 1977, 25, 483-519.

Rioux J.A., Dereure J. \& Perières J. Approche écologique du risque épidémiologique. L'exemple des leishmanioses. Bulletin d'Écologie, 1990, 21 (1), 1-9.

Rioux J.A., Golvan Y.J., Croset H., Tour S., Houin R., Abonnenc E., Petitdidier M., Vollhardt Y., Dedet J.P., Albaret J.L., Lanotte G. \& Quilici M. Épidémiologie des leishmanioses dans le sud de la France. Monographies INSERM. Vol. 37, Paris, 1969, 223 p.

Rioux J.A., Lanotte J., Cousserans A., Gabinaud J.J. \& Corre J.J. Écologie, développement et santé publique. Bases écologiques de l'analyse d'un système épidémiologique; foyers d'infection et parasitocoenose; stratégies d'enquêtes et d'intervention. Bulletin du CNRS, 1981, 245-254.

Rogers D.J. Satellites, space, time and the African trypanosomiasis. Advances in Parasitology, 2000, 47, 129-171.

Scholthof K.B.G. The disease triangle: pathogens, the environment and society. Nature Reviews, 2007, 5, 152-156.

Siddig A., Al Jowary S., Al Izzi M., Hopkins J., Hall M. \& SlinGENBERGH J. Seasonality of Old World screwworm myiasis in the Mesopotamia valley in Iraq. Medical and Veterinary Entomology, 2005, 19, 140-150.

Traub R.J., Monis P.T. \& RoberTson I.D. Molecular epidemiology: a multidisciplinary approach to understanding parasitic zoonoses. International Journal for Parasitology, 2005, 35, 1295-1307.

Wiens J.A., Moss M.R., Turner M. \& Mladenoff D.J. Foundation papers in Landscape Ecology. Columbia University Press, New York, 2007.

Yang G., Vounatsou P., Zhou X., Utzinger J. \& Tanner M. A review of geographic information system and remote sensing with applications to the epidemiology and control of schistosomiasis in China. Acta tropica, 2005, 96, 117129.

Yang Y., Ellis M., Sun T., Li Z., Liu X., Vuitton D., Bartholomot B., Giraudoux P., Craig P., Boufana B., Wang Y., Feng X., Wen H., Ito A. \& McManus D. Unique family clustering of human echinococcosis cases in a chinese community. American Journal of Tropical Medicine and Hygiene, 2006, 74 (3), 487-494. 